\title{
Characteristics of acute care utilization of a Delaware adult sickle cell disease patient population.
}

\author{
Nina Anderson \\ School of Nursing, Thomas Jefferson University, Nina.Anderson@jefferson.edu \\ Jennifer L. Bellot \\ School of Nursing, Thomas Jefferson University, jennifer.bellot@jefferson.edu \\ Oluseyi Senu-Oke \\ Delaware Physicians Association, Wilmington, Delaware \\ Samir K. Ballas \\ Thomas Jefferson University School of Medicine, samir.ballas@jefferson.edu
}

Follow this and additional works at: https://jdc.jefferson.edu/dnpp

Let us know how the Occial Specilties commons
Let us to this document benefits you

\section{Recommended Citation}

Anderson, Nina; Bellot, Jennifer L.; Senu-Oke, Oluseyi; and Ballas, Samir K., "Characteristics of acute care utilization of a Delaware adult sickle cell disease patient population." (2014).

Department of Nursing papers and presentations. Paper 14.

https://jdc.jefferson.edu/dnpp/14

This Article is brought to you for free and open access by the Jefferson Digital Commons. The Jefferson Digital Commons is a service of Thomas Jefferson University's Center for Teaching and Learning (CTL). The Commons is a showcase for Jefferson books and journals, peer-reviewed scholarly publications, unique historical collections from the University archives, and teaching tools. The Jefferson Digital Commons allows researchers and interested readers anywhere in the world to learn about and keep up to date with Jefferson scholarship. This article has been accepted for inclusion in Department of Nursing papers and presentations by an authorized administrator of the Jefferson Digital Commons. For more information, please contact: JeffersonDigitalCommons@jefferson.edu. 


\title{
Characteristics of Acute Care Utilization of a Delaware Adult Sickle Cell Disease Patient Population
}

\author{
Nina Anderson, DNP, RN, FNP-BC, Jennifer Bellot, PhD, RN, MHSA, \\ Oluseyi Senu-Oke, MD, and Samir K. Ballas, $\mathrm{MD}^{3}$
}

\begin{abstract}
Sickle cell disease (SCD) is an inherited blood disorder that is chronic in nature and manifests itself through many facets of the patient's life. Comprehensive specialty centers have the potential to reduce health care costs and improve the quality of care for patients who have chronic medical conditions such as heart failure and SCD. The purpose of this practice inquiry was to analyze de-identified data for acute care episodes involving SCD in order to create a detailed picture of acute care utilization for adult patients in Delaware with SCD from 2007 to 2009. Gaining a better understanding of acute care utilization for adults with SCD may provide evidence to improve access to high-quality health care services for this vulnerable patient population in the state of Delaware. (Population Health Management 2014;17:60-65)
\end{abstract}

\section{Introduction}

$\mathbf{T}$ HE CHALlENGES OF MANAGING PATIENTS with complex chronic conditions, such as adults with sickle cell disease (SCD), call for an exploratory analysis of acute care utilization for adults with SCD in Delaware. Understanding the landscape of acute care visits can inform a strategic plan of action to improve access to high-quality care services and reduce overall health care expenditures for these patients. SCD primarily affects people of African descent, and the sickle gene mutation is prevalent in the Caribbean, Mediterranean, Indian, and other geographic regions in which malaria is also prevalent. Under conditions of deoxygenation of the sickle hemoglobin, red blood cells sickle and change shape, leading to vaso-occlusion that deprives body tissues and organs of needed circulation and oxygenation. This causes excruciating pain that, over time, can damage the blood vessels and major organs. $^{1}$

SCD is associated with significant morbidity and mortality. Medical complications associated with the disease include: stroke, retinopathy, pulmonary hypertension, chronic pain, avascular necrosis of the hips and shoulders, leg ulcers, increased vulnerability to infections, blood transfusion reactions, alloimmunization, multiorgan damage (lungs, kidneys, spleen), psychological distress, depression, substance abuse, and opioid tolerance or dependency. Nonmedical complications include unemployment, lack of education and vocational training, lack of transportation, and disability (S.K. Ballas, MD, unpublished data, October 2011; O. SenuOke, MD, unpublished data, June 2011).

\section{Significance}

As the population ages and US health care changes because of implementation of the Patient Protection and Affordable Care Act, there are major implications to address the fundamental infrastructure for providing comprehensive specialty care and services for patients with complex chronic medical conditions. SCD is a chronic medical condition that incurs a significant cost burden for the care of adult patients. The total annual prorated fees (assuming a 6\% inflation increase per year) for an adult SCD patient were estimated at $\$ 725,037$ in 2008; it is estimated that the total undiscounted costs (SCD-related and non-SCD-related) could reach $\$ 953,640$ for a person reaching 45 years of age. ${ }^{2,3}$ The management of SCD can become costly because of the chronicity and the recurrence of exacerbations.

\section{SCD Landscape in Delaware}

Children with SCD in the state of Delaware have access to a comprehensive sickle cell program at a large pediatric hospital, which also has a satellite clinic in Sussex County. Once a patient reaches adulthood and must transition out of the pediatric program (between ages 18 to 21 years), there is

\footnotetext{
${ }^{1}$ Jefferson School of Nursing, Philadelphia, Pennsylvania.

${ }^{2}$ Delaware Physicians Associates, Wilmington, Delaware.

${ }^{3}$ Thomas Jefferson University School of Medicine, Philadelphia, Pennsylvania.
} 
no adult comprehensive specialty center in Delaware to provide patients with continued high-quality, patientcentered care by their primary care provider or hematologist, including psychosocial support and resources for this vulnerable patient population. In the surrounding geographic area (ie, New Jersey, Pennsylvania, Maryland), Delaware is the only state that does not provide funding for an adult comprehensive specialty SCD center. For this reason, SCD care and management may be subject to fragmentation, less coordination, and increased utilization of acute care services.

\section{Epidemiology}

Approximately 100,000 people (1 in every 500 African American births) in the United States live with SCD. Over 2.5 million people ( 1 in 12 people) of African descent carry the trait. People of Hispanic descent are the fastest growing ethnic group in the United States with SCD. It is estimated that over 750 people in the state of Delaware live with SCD, more than 350 of whom are adults (18 years of age and older) (O. Senu-Oke, MD, unpublished data, June 2011). ${ }^{4-6}$

\section{Purpose}

The purpose of this practice inquiry (PI) was to analyze de-identified data for acute care episodes involving SCD in order to create a detailed picture of acute care utilization for adult patients in Delaware with SCD from 2007 to 2009. The aim of this PI was to determine the characteristics of acute care utilization, health care expenditures, and acute care costs for adult SCD patients in order to determine whether a comprehensive adult SCD specialty care is needed in Delaware.

\section{Literature review}

A review of the literature included a search of PubMed, Scopus, and CINAHL databases. Articles examined addressed the barriers for adults with SCD, hospital readmission within 30 days, and costs to provide care for adult SCD patients. The findings from the articles were further reviewed and critiqued for content, sorted by topic, and synthesized to find evidence to inform the PI.

Costs. The Healthcare Cost and Utilization Project (HCUP) examined the characteristics of 113,098 SCD hospitalizations of adults and children nationwide from 1994 to 2004. The number of SCD-related hospitalizations for adults in 2004 remained statistically unchanged at 83,149 per year, equivalent to the number of hospitalizations in 1997. A large percentage of hospital admissions for SCD (75\%) came via the emergency room (ER) in 2004. Approximately two thirds of the adult SCD patients hospitalized were 18-44 years of age; $31 \%$ received a blood transfusion, $25 \%$ had an infection, $14 \%$ had a pulmonary condition, and $18 \%$ had a substancerelated or other mental health disorder. More than $75 \%$ of all hospital patient stays for adults and children were billed to Medicare or Medicaid. In 2004, the total hospital costs for all SCD patients reached $\$ 488$ million; average cost per hospital stay was $\$ 6223$. $^{7}$

Kauf et al examined the estimated cost of care for 4294 adults and children with SCD. ${ }^{3}$ The study found that more than $80 \%$ of SCD-related costs for Florida Medicaid patients during 2001-2005 were associated with acute care and ER visits, and only $1 \%$ was associated with outpatient physician visits. The median lifetime discounted and undiscounted costs (SCD-related and non-SCD-related) were estimated to be between $\$ 186,406$ and $\$ 392,940$. Lanzkron et al also examined the costs of adult SCD care using Maryland Hospital Discharge Data collected from fiscal year (FY) 1995 to FY2003. ${ }^{8}$ The hospitalization costs increased from $\$ 9.8$ million in FY1995 to $\$ 15.6$ million in FY2003 $(P<0.001)$. The total costs for inpatient adult SCD care were $60 \%$ higher, even after adjusting for inflation (producer price index) during the years of data analysis. Woods et al examined hospital utilization patterns of 1189 adult SCD patients in Illinois in 1992 and 1993. ${ }^{9}$ The total charges for adult SCD hospital admissions during the 2-year study period were over \$59 million, or approximately \$30 million per year. The most common admitting diagnosis was for vaso-occlusive pain crisis (97.4\%); a large majority of patients $(85.7 \%)$ were admitted through the ER. ${ }^{9}$

Further, national estimates of ER utilization for 50,418 SCD-related ER visits were analyzed from the Nationwide Emergency Department Sample in 2006. The study found that combined overall costs for ER and hospital visits for children and adults with SCD were $\$ 2.4$ billion, which is a significant cost burden. ${ }^{10}$ A study found that SCD patients in Alabama who were enrolled in a comprehensive specialty SCD clinic used the ER and were hospitalized less frequently than those patients who were not enrolled in the clinic. The $33.5 \%$ of these patients who did not utilize services at specialty clinics constituted $71.4 \%$ of ER visits and $42.3 \%$ of hospital admissions. ${ }^{11}$ There was a significant reduction in the total cost of care for patients who attended these clinics.

Hospital readmissions. Ballas and Lusardi examined hospital admissions for adults with SCD hemoglobin SS-type (SCD-SS) from 1998 to 2002 at Thomas Jefferson University Hospital in Philadelphia, Pennsylvania. ${ }^{12}$ One hundred eighty-two patients with SCD-SS type were followed prospectively and longitudinally for hospital discharge patterns. The results revealed that 136 patients were admitted 1540 times with an average length of stay (LOS) of 7.6 days. There were $228(16 \%)$ readmissions within 1 week of discharge, and $726(50 \%)$ readmissions within 1 month of discharge. Readmissions were more frequent for males (70\%) than females. Pain intensity scores in the severe range at discharge increased the risk of hospital readmission. Characteristics of narcotic withdrawal symptoms were reported by 55 patients who were readmitted within 1 week, and 78 patients who were readmitted within 1 month of hospital discharge. A retrospective cohort study by Brousseau et al found SCDrelated 30-day rehospitalization rates in 8 geographically dispersed states to be $33 \%$ for all ages. ${ }^{13}$ The study also found that hospital readmission within 14 days of a previous admission was $28 \%$, and that the 30-day hospital readmission rate was highest for adult SCD patients ages 18-30 years $(41 \%)$. The 7 -day hospital readmission rate was not reported in this study. Overall, hospital readmissions were highest for patients who were publicly insured.

Another study examined the risk factors for hospital readmissions within 30 days of discharge for children with SCD at a St. Louis, Missouri hospital during 2005-2006. Of the 105 SCD patients meeting inclusionary criteria, 30 were 
readmitted within 30 days of discharge; $50 \%$ of these children were readmitted within 8 days of discharge and $77 \%$ were readmitted within 21 days of discharge. Twenty-four percent of patients who were admitted for short-stay admissions and discharged after 24 hours were readmitted. ${ }^{14}$

Research in the literature review supports the importance of adult SCD patients having access to comprehensive specialty care run by a principal health care provider and an experienced team of health care professionals, both medical and nonmedical, who are knowledgeable about SCD management and treatment.

\section{Methods}

\section{Practice design and methodology}

The researcher (NA) used quantitative exploratory analysis and descriptive statistics to determine relationships between the variables selected: age, insurance type, patient zip code of residence, patient county of residence, number of hospital admissions, number of hospital readmissions within 7 and 30 days, hospital costs, LOS, total acute care costs, and International Classification of Diseases, Ninth Revision (ICD-9) codes for visits at 3 local hospitals in order to obtain a descriptive picture of acute care utilization services for adults with SCD in Delaware from 2007 to 2009. De-identified data were extracted from Delaware hospital discharge records stored at the Office of Vital Statistics and sorted from a secured zip file with permission from the Delaware Department of Health and Social Services (DHSS) and Thomas Jefferson University's Institutional Review Board.

\section{Inclusion and exclusion criteria}

Inclusion criteria were adult residents with SCD who received acute care at 1 small community hospital and 1 large community hospital system from 2007 to 2009. Exclusion criteria were patients younger than 18 years of age with no ICD-9 code associated with SCD who were admitted to a Sussex County hospital and a large pediatric hospital in Delaware.

Acute care utilization for SCD was extracted from compulsory hospital discharge data that Delaware hospitals report to the DHSS Office of Vital Statistics (Delaware Department of Health and Social Services, unpublished data, 2012). Data were abstracted from 1 community hospital and 2 hospital systems located in New Castle and Kent Counties because $90 \%$ SCD of patients resided in these counties. Therefore, it was presumed that adult SCD patients utilized hospitals in these counties for their acute SCD needs. The data included adults aged 18 years and older at admission with a primary or secondary diagnose(s) of SCD and who resided in Delaware. The patient's sex, hydroxyurea use, SCD genotype, and data from ER visits not resulting in inpatient admission were not accessible to the researcher.

\section{Statistical analysis}

Frequencies were run on the following variables: age, insurance type, zip code, county, primary ICD-9 code, hospital costs, LOS, readmissions, and visits for analysis. Descriptive statistics were run on age, LOS, and hospital costs to determine the distribution of the data. Crosstabs were run to compare all variables within each data set to determine
Table 1. DHSS Acute Care Utilization Data SET 2007-2009

\begin{tabular}{lccc}
\hline & \multicolumn{3}{c}{ Year } \\
\cline { 2 - 4 } & 2007 & 2008 & 2009 \\
\hline Visits & 151 & 165 & 202 \\
Mean Costs per & $\$ 14,940$ & $\$ 14,584$ & $\$ 16,287$ \\
inpatient stay & & & $\$ 11,218$ \\
Median Costs & $\$ 10,291$ & $\$ 9,732$ & 32.5 years \\
Mean age & 32.3 years & 34.9 years & 31 years \\
$\quad$ Median & 30 years & 33 years & 6.7 days \\
Mean LOS & 7.9 days & 6.6 days & 5 days \\
Median & 5 days & 5 days & 66 \\
Readmit within & 38 & 44 & 23 \\
30 days & & & 12 \\
Readmit within & 8 & & $\$ 3.3$ million \\
$\quad 7$ days & & $\$ 2.4$ million &
\end{tabular}

DHSS, Department of Health and Social Services; LOS, length of stay.

relationships between and among variables. Notable findings included: $86 \%$ of adult SCD acute care hospital visits were billed to public insurers, $75 \%$ of acute care visits were in New Castle County, and 69\% utilized City-Suburban Health System. Overall, publicly insured adult SCD patients had longer hospital LOS than privately insured adult SCD patients.

\section{Results}

There were 518 acute care episodes from 2007 to 2009 (Table 1). The most recent and complete data set provided was in 2009; this was analyzed along with the trends from previous years.

Results from 2009 data show that there were 96 discrete adult SCD patients in the data sets, totalling 202 hospital visits in 2009. Utilization data for 2007-2009 are shown in Table 1. The 202 adult SCD patients had more hospital visits in New Castle County $(140 / 202)$ than in Kent County $(62 / 202)$.

\begin{tabular}{|c|c|c|c|}
\hline & $\begin{array}{c}\text { City- } \\
\text { Suburban }\end{array}$ & $\begin{array}{l}\text { Suburban- } \\
\text { Rural }\end{array}$ & City \\
\hline $\begin{array}{l}\text { County } \\
\text { Visits }\end{array}$ & $\begin{array}{c}\text { New Castle } \\
357\end{array}$ & $\begin{array}{c}\text { Kent } \\
119\end{array}$ & $\begin{array}{c}\text { New Castle } \\
42\end{array}$ \\
\hline $\begin{array}{l}\text { Mean Costs } \\
\text { Median Costs }\end{array}$ & $\begin{array}{l}\$ 15,724 \\
\$ 10,823\end{array}$ & $\begin{array}{l}\$ 14,912 \\
\$ 10,633\end{array}$ & $\begin{array}{c}\$ 13,431 \\
\$ 9,460\end{array}$ \\
\hline $\begin{array}{l}\text { Mean LOS } \\
\text { Median LOS }\end{array}$ & $\begin{array}{l}7.8 \text { days } \\
6 \text { days }\end{array}$ & $\begin{array}{l}5.6 \text { days } \\
4 \text { days }\end{array}$ & $\begin{array}{l}4.6 \text { days } \\
3 \text { days }\end{array}$ \\
\hline $\begin{array}{l}\text { Readmit } w / n \\
30 \text { days }\end{array}$ & 104 & 32 & 12 \\
\hline $\begin{array}{l}\text { Readmit } \mathrm{w} / \mathrm{n} \\
7 \text { days }\end{array}$ & 26 & 12 & 5 \\
\hline Total Costs & $\$ 5.6$ million & $\$ 1.8$ million & $\$ 564,124$ \\
\hline
\end{tabular}

Hospitals in Sussex County were not analyzed.

DHSS, Department of Health and Social Services; LOS, length of 
The minimum cost of SCD acute care utilization reported in the data set was $\$ 1800$ (LOS 1 day) and the maximum acute care utilization cost was $\$ 137,073$ (LOS 43 days). The data showed that $84 \%$ of patients with acute care visits were publicly insured, $47 \%$ by Medicaid $(94 / 202)$ and $37 \%$ by Medicare $(75 / 202) ; 11 \%$ of patients with acute care visits carried private insurance coverage and 5\% were uninsured. Secondary insurance type, if applicable, could not be determined from the data provided. It was found that $99.5 \%$ visits were ICD-9 coded for vaso-occlusive crisis as the primary diagnosis for the hospital visit. The 7-day rehospitalization rate was $11 \%$ and 30 -day rehospitalization rate in 2009 was $33 \%$ and for SCD-related causes (Table 2).

From 2007 to 2009, there was a 24\% increase in Medicaid insured acute care visits and a $10 \%$ increase in uninsured visits. Although there was a small percentage of patients with private insurance, there was a 50\% increase in acute care visits. The mean inpatient hospital cost per year for an adult SCD patient increased 8.3\% from 2007 to 2009; median costs increased by the same percentage for the same time period (Table 1). Mean inpatient LOS decreased 15\% from 2007 to 2009, while median LOS stayed the same for the same time frame (Table 1). The highest hospital costs were $\$ 244,861$, paid by Medicaid, for a 62-year-old patient whose LOS was 105 days in 2007. Acute care utilization for adults with SCD tripled in Kent County from 2007 to 2009 (13/151 to 53/202). The adult SCD patients who utilized hospitals from 2007 to 2009 lived in New Castle County, (389/518), Kent County (93/518), and Sussex County (36/518) (Table 2).

\section{Comparison of data to other geographic areas}

Comparing Delaware SCD data to national and other states' total hospital costs, LOS, and hospital cost averages was a challenge (Table 3). Each data set defined variables differently, which presented a challenge to pure data comparison. Neither the HCUP nor the Connecticut study reported yearly mean or median hospital costs, except for total hospital visit cost. ${ }^{15}$ It can be concluded that there needs to be better standardized methodology to determine hospital costs for adult SCD inpatient hospital care; therefore, it is difficult to make accurate comparisons for acute care hospital costs.

\section{Discussion}

In light of the findings, characteristics of acute care utilization for adult SCD patients in Delaware found that acute care hospital inpatient costs are steadily rising, which is reflective of national trends. Hospital readmissions within 7 and 30 days also have increased, but hospital LOS for acute care visits has remained fairly constant. Moreover, HCUP has found that over 75\% of hospital visits for SCD nationwide were billed to public insurers. ${ }^{7}$ The majority $(82.4 \%)$ of adult SCD patients who resided in the state of Delaware in 2009 were publicly insured and $4.8 \%$ were uninsured, which is slightly higher when benchmarking against data from HCUP (Delaware Department of Health and Social Services, unpublished data, 2012). Therefore, the majority of adults with SCD rely on public health insurance plans for their medical care, which are funded with public taxpayer dollars.

\section{Readmissions}

Reducing hospital readmission rates has attracted the attention of public policymakers to develop a plan of action to improve the quality of health care delivery in the hospital while containing Medicare costs. The Medicare Payment Advisory Commission (MedPAC) mandates that hospitals with high risk-adjusted rehospitalization rates receive lower payments for preventable hospital readmissions. MedPAC reported that Mediare expenditures for potentially preventable rehospitalizations may be as high as $\$ 12$ billion a year. A study of SCD hospitalizations in a geographically dispersed area found 30-day rehospitalization rates to be $33 \%$ for all ages. ${ }^{13}$ In Delaware in 2009, the 7-day rehospitalization rate was $11 \%$ and the 30 -day rehospitalization rate was $33 \%$.

\section{Costs}

Delaware's adult SCD acute care median hospital costs and LOS were lower than the mean hospital costs and LOS because data distribution of median hospital costs was more symmetric and less skewed. Therefore, the median hospital costs were a more accurate comparison of SCD acute care utilization in Delaware (Fig. 1). With evidence that Delaware SCD costs increased almost $10 \%$ from 2007 to 2009, inpatient

Table 3. Comparison of Adult SCD Hospital Inpatient Care

\begin{tabular}{|c|c|c|c|c|}
\hline & $\begin{array}{c}\text { Delaware } \\
2009\end{array}$ & $\begin{array}{c}\text { Connecticut } \\
2005\end{array}$ & $\begin{array}{c}\text { National }^{2} \\
2004\end{array}$ & $\begin{array}{c}\text { PA Hospital } \\
2005\end{array}$ \\
\hline Visits & 202 & Not reported & 83,149 (2004) & 1540 \\
\hline & Adults & Adults & Adults \& Children & Adult \\
\hline Mean Costs & $\$ 16,287$ & Not reported & Not reported & Not reported \\
\hline $\begin{array}{c}\text { Mean LOS } \\
\text { Median }\end{array}$ & $\begin{array}{l}6.7 \text { days } \\
5 \text { days }\end{array}$ & 8.7 days & 5.5 days & 7.6 days \\
\hline Readmit w/n 30 days & $33 \%$ & Not reported & Not reported & $\sim 50 \%$ SS-type \\
\hline Readmit w/n 7 days & $11 \%$ & Not reported & Not reported & $\sim 16 \%$ SS-type \\
\hline Hospital Total Costs & $\$ 3.3$ million & $\$ 10.7$ million & $\$ 488$ million & Not reported \\
\hline
\end{tabular}

\footnotetext{
${ }^{1}$ The average length of stay (LOS) and data were taken from the Connecticut Health Information Exchange Data (CHIME) for inpatient admissions, hospital-based ambulatory surgery, and emergency department visits for all thirty (30) of Connecticut's acute care hospitals. ${ }^{18}$

${ }^{2}$ The national Healthcare Cost and Utilization Project (HCUP) data for SCD patient characteristics, costs of hospital stays, and outcomes from 1994-2004. ${ }^{9}$

${ }^{3}$ The PA Hospital data was taken from American Journal of Hematology. ${ }^{14}$

LOS, length of stay; SCD, sickle cell disease.
} 


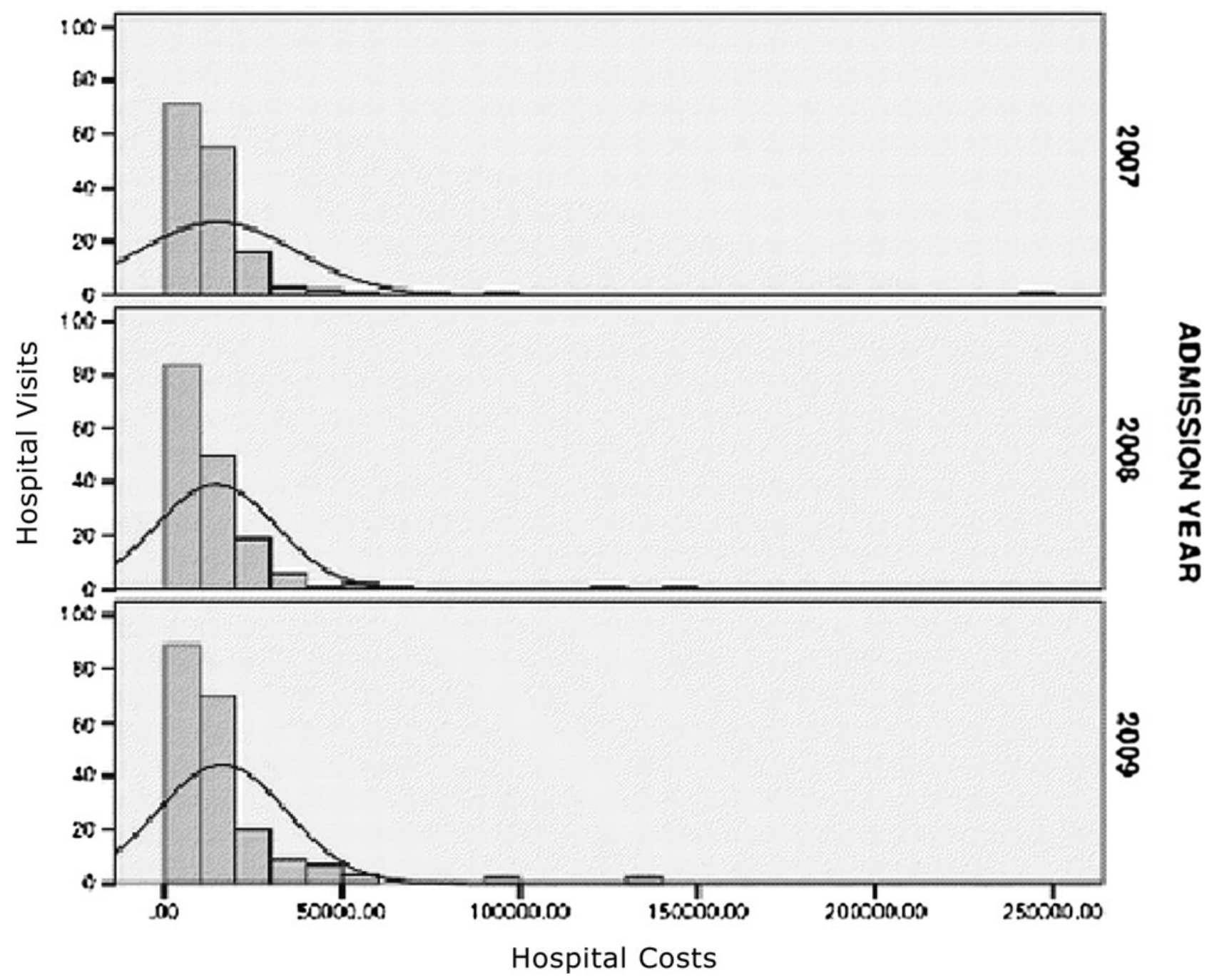

FIG. 1. Data distribution for total hospital costs.

LOS had less change, respectively. Further analysis of hospital costs for outlier patients on the higher end of the distribution curve who positively skewed the data may better explain the differences between the mean and median costs.

In this study, the high percentage $(99.5 \%)$ of hospital admissions from the ER for vaso-occlusive crisis further demonstrates that there is a need for more integrated, coordinated care services that can provide transitional care services to reduce hospital readmissions and increase access to a statewide community-based comprehensive specialty care. 2,13,19 Access to disease modifying therapies, such as hydroxyurea utilization, are facilitated by access to comprehensive specialty SCD care clinics. Hydroxyurea has been shown to reduce hospital admission rates by $40 \%-50 \%$ in adult SCD patients who respond to the medication. ${ }^{16-18}$

\section{Limitations}

Observation of the data sets found positive skewness and kurtosis in the asymmetry of distribution of the total charges and LOS; therefore, the mean total charges and LOS were $40 \%-50 \%$ higher than the median (Fig. 1). This may indicate that further study is needed to analyze high SCD acute care patient utilization patterns and their access to disease modifying therapies such as hydroxyurea. The age variable in the data set was more evenly distributed and only slightly skewed. Data were not available to determine the costs for ER visits for patients discharged to home, prescription costs, hydroxyurea usage, transportation costs, and visits in the outpatient setting (ambulatory care and physician visits). The HCUP sampling frame was limited to $90 \%$ of all hospital discharges in the United States, and coding errors may have increased the overall SCD costs in the hospital stay data. ${ }^{7}$ Further exploration of these costs will determine total health care costs and LOS more effectively for SCD adult care in Delaware. Those costs can then be benchmarked against national findings in a more pure data set comparison; currently, each data set defined variables differently.

\section{Conclusion}

Overall, the cost of acute care utilization for SCD vasoocclusive episodes is increasing in the adult SCD population. There is an urgent need to reduce health care costs and increase access to high-quality care, especially for socioeconomically disadvantaged and vulnerable patient populations. The state of 
Delaware would benefit from an adequately resourced, integrated, statewide community-based adult SCD comprehensive specialty program to increase patient access to high-quality care and reduce health care costs. Overall, the future of SCD awareness, treatment, management, and research remains uncertain; however, increasing acute care costs for adults with SCD pose a significant taxpayer burden as the cost of health care continues to rise.

\section{Acknowledgments}

The authors would like to thank John Washington, RN, $\mathrm{MPH}$, Andrew Cucchiara, PhD, Carlton Dampier, MD, Sophie Lanzkron, MD, and Bethany Hall-Long, PhD, RN, FAAN for sharing their knowledge and expertise. The authors also thank the Delaware Department of Health and Social Services for providing the hospital data for analysis.

\section{Author Disclosure Statement}

Drs. Anderson, Bellot, Senu-Oke, and Ballas declared no conflicts of interest nor financial support with respect to the research, authorship, and/or publication of this article.

\section{References}

1. Brawley O, Cornelius LJ, Edwards LR, et al. National Institutes of Health Consensus Development Conference statement: Hydroxyurea treatment for sickle cell disease. Ann Intern Med 2008;148:932-938.

2. Ballas SK. The cost of health care for patients with sickle cell disease. Am J Hematol 2009;84:320-322.

3. Kauf TL, Coates TD, Huazhi L, Mody-Patel N, Hartzema AG. The cost of health care for children and adults with sickle cell disease. Am J Hematol 2009;84:323-327.

4. Agency for Healthcare Research and Quality. National Health Disparities Report. Rockville, MD: Agency for Healthcare Research and Quality; 2008.

5. Hassell KL. Population estimates of sickle cell disease in the U.S. Am J Prev Med 2010;38:S512-S521.

6. Rodgers JE. Breaking the "sickle cycle." Abell Report 2011; 24:1-12.

7. Steiner C, Miller J. (2006, December). Sickle cell disease patients in U.S. hospitals, 2004. Healthcare Cost and Utilization Project: Agency for Healthcare Research and Quality. http:// www.hcup-us.ahrq.gov/reports/statbriefs/sb21.pdf. Accessed December 2006.

8. Lanzkron S, Haywood C Jr, Segal JB, Dover GJ. Hospitalization rates and costs of care of patients with sickle-cell anemia in the state of Maryland in the era of hydroxyurea. Am J Hematol 2006;81:927-932.

9. Woods K, Karrison T, Koshy M, Patel A, Friedmann P, Cassel C. Hospital utilization patterns and costs for adult sickle cell patients in Illinois. Public Health Rep 1997;1:44-51.

10. Lanzkron S, Carroll C, Haywood C Jr. The burden of emergency department use for sickle cell disease: An analysis of the national emergency department sample database. Am J Hematol 2010;85:797-799.

11. Yang YM, Shah AK, Watson M, Mankad VN. Comparison of costs to the health sector of comprehensive and episodic health care for sickle cell disease patients. Public Health Rep 1995;110:80-86.

12. Ballas SK, Lusardi M. Hospital readmission for adult acute sickle cell painful episodes: Frequency, etiology, and prognostic significance. Am J Hematol 2005;79:17-25.

13. Brousseau DC, Owens PL, Mosso AL, Panepinto JA, Steiner CA. Acute care utilization and rehospitalizations for sickle cell disease. JAMA 2010;303:1288-1294.

14. Frei-Jones MJ, Field JJ, DeBaun MR. Risk factors for hospital readmission within 30 days: A new quality measure for children with sickle cell disease. Pediatr Blood Cancer 2008;52:481-485.

15. Connecticut Department of Public Health. Designing a comprehensive system across the lifespan: Connecticut state plan to address sickle cell disease and trait. Connecticut Comprehensive Sickle Cell Disease Consortium. http:// www.ct.gov/dph/lib/dph/sickle_cell_plan-final_12-28-07 .pdf. Accessed December 2007.

16. Cherache S, Terrin ML, Moore RD, et al. Effect of hydroxyurea on the frequency of painful crisis in sickle cell anemia. New Engl J Med 1995;332:1317-1322.

17. Platt OS. Hydroxyurea for the treatment of sickle cell anemia. New Engl J Med 2008;358:1362-1369.

18. National Heart, Lung and Blood Institute [NHLBI]. The Management of Sickle Cell Disease. 4th ed. Bethesda, MD: NHLBI; 2002.

19. Jenks S, Williams M, Coleman E. Rehospitalizations among patients in the Medicare fee-for-service program. New Engl J Med 2009;360:1418-1428.

Address correspondence to: Nina Anderson, DNP, RN, FNP-BC Jefferson School of Nursing 901 Walnut Street, 8th Floor Philadelphia, PA 19107

E-mail: contact@tovahealthcare.com 